способность принимать нестандартные решения, дружелюбие и предприимчивость.

Вполне очевидно расхождение мнений респондентов по размеру заработной платы: работодатели объясняют низкий начальный уровень слабыми профессиональными навыками и затратами на обучения, в то время как молодые специалисты в качестве оценки на первое место ставят наличие собственных потребностей.

Среди каналов, которые используются для привлечения молодых специалистов работодатели наиболее эффективными отмечают рекомендации и объявления в СМИ и социальных медиа (около 60\%), направление службой занятости (52\%), ярмарки вакансий (около 30\%). Но более $80 \%$, по мнению работодателей обращаются в компанию сами, ориентируясь на репутацию и престиж. Большинство молодых специалистов отметили, что личное общение с будущим боссом наиболее эффективный метод, в то время как остальные каналы имеют меньшее влияние.

Среди основных проблем работодатели отметили несоответствие спроса и предложений на рынке труда (более 70\%), что подтвердили 42\% молодых специалистов, которые главным негативным фактором видят желание компании быстро получить результат при низких затратах на зарплату, обучение и адаптацию (более 57\%.)

Таким образом можно сделать вывод, что при выборе специальности молодые люди чаще ориентируются на интерес, отчасти учитывают фактор спроса и предложения, что подчёркивает необходимость усиления профориентационной работы с потенциальными кандидатами. В процессе исследования удалось выявить, разные взгляды, на первоначальную заработную плату со стороны работодателя и молодого специалиста, что зачастую связано с желанием первого получить быстрый результат и при этом не нести затрат на обучение. Что касается молодого специалиста, то вопрос заработной платы для него измеряется потребностями, а не компетенциями, из чего следует вывод, что нужно постоянно повышать уровень своих профессиональных знаний.

\title{
Умархаджиева C.P. \\ Проблемы обязательного медицинского страхования в России и пути их решения
} ФГБОУ ВО Чеченский государственный университет doi: 10.18411/lj-04-2021-310 (Россия, Грозный)

\section{Аннотация}

В представленной статье рассматриваются ключевые вопросы реализации системы обязательного медицинского страхования в России. В конце приводятся основные мероприятия необходимые для совершенствования системы ОМС России.

Ключевые слова: обязательное медицинское страхование, страховые взносы, социальная гарантия, страховая система.

\section{Abstract}

The presented article examines the key issues of the implementation of the compulsory health insurance system in Russia. At the end, the main measures necessary to improve the compulsory health insurance system in Russia are given.

Key words: compulsory medical insurance, insurance premiums, social guarantee, insurance system.

В настоящее время Россия обеспечивает обязательное медицинское страхование всего населения, которое покрывает часть расхода людей на медицинское обслуживание. Медицинское страхование определяется как «покрытие, которое 
предусматривает выплату пособий в результате болезни или травмы. Оно включает страхование от несчастных случаев, расходов на медицинское обслуживание, инвалидности или несчастного случая и смерти» [2, с.93]. Система обязательного медицинского страхования является одним из видов социального страхования, формой социальной защиты населения Российской Федерации. Поэтому изменения в политике ОМС, введение платных услуг населения в сфере ОМС должны быть тщательно продуманы.

Одним из важных моментов в ОМС является государственная гарантия соблюдения прав застрахованных лиц на защиту от страховых рисков и выполнение обязательств по ОМС независимо от финансового положения страховщика.

Согласно законодательству, источниками финансирования системы медицинского страхования являются средства из национальных и региональных бюджетов на всех уровнях, целевые фонды, государственные и муниципальные компании, организации, общественные объединения, доходы от оборот ценных бумаг, банковских кредитов или доходов от благотворительных и иных источников, не запрещенных законодательством Российской Федерации.

Финансовые ресурсы государственной системы создаются за счет застрахованного лица. Страховые взносы с предприятий, организации и компании выделяются на обязательное медицинское страхование сверх ассигнований, установленных для развития и функционирования здравоохранения. Федеральные и территориальные фонды, независимые некоммерческие финансово-кредитные учреждения, создаются для накопления страховых взносов на обязательное медицинское страхование. Для реализации государственной программы обязательного медицинского страхования созданы специальные федеральные и местные фонды с целью накопления необходимых финансовых ресурсов.

В принципе, социальные гарантии, обещанные гражданам, способствуют улучшению здоровья населения. Основное внимание в законодательстве уделяется управлению медицинскими организациями, игнорирующие вопросы программ по укреплению общественного здоровья.

Модель ОМС в России, по сути, служит для простого перевода денег из страховых фондов через страховые компании и, в конечном итоге, в медицинские учреждения, независимо от фактического объема оказанных услуг. Предполагается, что бюджетные ассигнования будут сохраняться на стабильном уровне и что премии, собранные фондами ОМС, будут дополнительным профицитом. Но на самом деле все средства на нужды здравоохранения должны работать отдельно и делиться на две части: старую (по государственным программам) и новую (по схеме страхования). Вторая часть сразу же создала собственную бюрократию, на данный момент заполненную большим количеством недостаточно квалифицированных кадров.

Один одной из основных целей медицинского страхования является улучшение финансирования здравоохранения, и до сих пор финансовое положение только ухудшилось. Страховая система должна функционировать через различные вклады, но на данном этапе два основных участника- - налоги на заработную плату и центральное правительство не выполняют свои обязанности. Здоровье остается с низким приоритетом для правительства, о чем свидетельствует распределение средств через внебюджетные фонды. Кроме того, даже если деньги откладываются во внебюджетный фонд, они часто исчезают. через коррупционные практики в банковской системе. На наш взгляд конечным результатом является дальнейшее ухудшение медицинской системы [3, с.140].

Российское законодательство в области здравоохранения требует серьезных пересмотров, а правовая база очень слабая и не содержит каких-либо конкретных руководящих принципов для эффективных механизмов управления. Ситуация более 
сложная из-за региональной асимметрии. Это объективная причина, препятствующая соблюдению единого стандарта управления для всех регионов.

Сегодня в отрасли складывается понимание, что управление такой сложной и многогранной структурой требует дифференцированного подхода и создания адекватной гибкой структуры (или внесения существенных изменений в существующую), основанной на квалифицированном персонале, который знает, как создавать и применять инструменты для реализации задач здравоохранения и снижения потерь в потенциальной и активной жизни населения.

В настоящее время наиболее востребованными направлениями совершенствования российской системы управления системы обязательного медицинского страхования являются:

- Резкое реформирование системы управления отраслью с целью ее гармонизации с создаваемой системой здравоохранения (или, по крайней мере, с ее прототипом).

- Совершенствование инструментов, отражающих условия социальноэкономического развития страны и отдельных регионов с точки зрения социальной направленности и социальной справедливости в здравоохранении.

- Обновление структурных, организационно-методических и мотивационных механизмов, повышающих уровень поддержки научных исследований и разработок, а также степень адаптации мирового опыта в системе здравоохранения.

- Разработка инструментов управления (в том числе на уровне правового и нормативного обеспечения), обеспечивающих эффективную (и зачастую определяющую жизнь) передачу решений и проектов в процессе вертикальных и горизонтальных перемещений в системе управления здравоохранением [1, с.69].

Особое внимание следует уделить следующему:

Реализация тенденции перехода функций управления с федерального на региональный уровень. Без соответствующей управленческой, правовой и нормативной поддержки это приводит к расхождениям в выработке эффективных управленческих решений в регионах (более того, это может вызвать - и часто приводит к - неудачам в реализации программ для регионов из-за неопределенности в законности определенных управленческих действий или может привести к неоправданным изменениям в управлении в регионах, что усложняет процесс управления).

Поддержка компетентностных функций органов здравоохранения на муниципальном уровне (поскольку на муниципальном уровне компетентностные характеристики являются первичными и основными, и их ограничение на этом уровне наносит непоправимый ущерб качеству медицинской помощи).

Совершенствование управления финансовыми потоками в отрасли с активной интеграцией методов управления экономикой, основанных не на «лоскутном» перераспределении выделяемых ресурсов, а на достижении целей с минимизацией законных и практически обоснованных затрат и эффективным использованием имеющихся средств [5, с.13].

Конечно, отсутствие четких руководящих принципов для создания российской модели здравоохранения и слабая работа по совершенствованию системы управления в отрасли не только негативно влияют на программно-ориентированный механизм системы здравоохранения, но часто искажают и даже отрицают все действия при достижении первичной цели, которые в конечном итоге превращаются в перечень обязательных мер, фрагментарный и без взаимосвязи. 
На наш взгляд российская система обязательного медицинского страхования нуждается в реформе из-за наличия ряда проблем: нехватка медицинского персонала (особенно в первичном звене) и диспропорция в его структуре. Недостаточная квалификация медицинского персонала, проблемы базового медицинского образования, отсутствие преемственности последипломного образования, недостаточное внедрение современных образовательных технологий; несистематическое управление, включая отсутствие стратегии развития здравоохранения, отсутствие ответственности и ответственности руководителей на всех уровнях за достижение результатов установленных показателей, а также неадекватные и противоречивые правовые рамки для охраны здоровья.

$$
* * *
$$

1. Агеева Н. Р. Страхование: теория, практика и зарубежный опыт: учебник / Н. Р. Агеева - М.: Юность, 2016. - 325 с.

2. Алещенко О.М., Никишина Н.В. Особенности и проблемы обязательного медицинского страхования в РФ // Финансовый вестник. 2016. № 3. С. 87-93.

3. Алиева Б. Х. Основы страхования: учебник / Б. Х. Алиев. - М.: ЮНИТИДАНА, 2014. - 503 с.

4. Романова Т. Ф. Страхование: теория и практика: научно-практическое пособие / Т. Ф. Романова. Ростов н/Д.: РГЭА, 2016. -287 с.

5. Федорова Т. А. Медицинское страхование и защита здоровья населения. / Т. А. Федорова // Финансы. - 2016. - № 10. - С. 9-18.

\section{Умархаджиева C.P. \\ Практические меры по эффективности социальной защиты семьи, материнства и детства в России \\ ФГБОУ ВО Чеченский государственный университет (Россия, Грозный)}

doi: 10.18411/lj-04-2021-311

\section{Аннотация}

В представленной статье определяется, что неблагоприятные социальные условия в семьях являются основными детерминантами, которые способствуют ухудшению здоровья, что ведет к росту заболеваемости и повышению спроса на медицинскую помощь. Поэтому необходима чётко продуманная государственная политика социальной защиты семьи, которая дает возможность восполнить недостатки как на индивидуальном, так и на семейном уровне, обеспечивая всеобщий доступ к услугам, льготам и трансфертам из государственных учреждений.

Ключевые слова: семья, социальное обеспечение семьи и детства, социальная политика, социальное пособие.

\section{Abstract}

This article identifies that unfavorable social conditions in families are the main determinants that contribute to poor health, which leads to an increase in morbidity and an increase in demand for medical care. Therefore, a well-thought-out state policy of social protection of the family is needed, which makes it possible to fill the shortcomings at both the individual and family levels, ensuring universal access to services, benefits and transfers from public institutions. benefit.

Key words: family, social security of family and childhood, social policy, social

Важность вопросов защиты семьи как стратегического направления социальной политики страны, неоднократно становилась темой обсуждений Президента РФ: «создание условий для роста рождаемости, охрана материнства и детства, укрепление 